\title{
Satisfaction towards the services provided by the community pharmacist in north-west India: A qualitative exploratory study
}

\author{
Manik Chhabra $^{\mathrm{a}}$, Sai Krishna Gudi ${ }^{\mathrm{b}}$, Muhammed Rashid ${ }^{\mathrm{c}, *}$, Aditya Goyal ${ }^{\mathrm{d}}$, \\ Raman Kumar Tripathi ${ }^{a}$, Ananth Kashyap ${ }^{e}$ \\ ${ }^{a}$ PharmD Inten, Department of Pharmacy Practice, Indo-Soviet Friendship College of Pharmacy, Moga, Punjab, India \\ ${ }^{\mathrm{b}}$ Department of Pharmacy, Rady Faculty of Health Sciences, University of Manitoba, Canada \\ ${ }^{\mathrm{c}}$ Assistant Professor, Department of Pharmacy Practice, Sri Adichunchanagiri College of Pharmacy, Adichunchanagiri University, $B$ G Nagara, Karnataka, India \\ ${ }^{\mathrm{d}}$ B Pharm Graduate, Department of Pharmaceutical Sciences, Indo-Soviet Friendship College of Pharmacy, Moga, Punjab, India \\ ${ }^{\mathrm{e}}$ Department of Pharmacy Practice, Sarada Vilas College of Pharmacy, Mysuru, Karnataka, India
}

\section{A R T I C L E I N F O}

\section{Keywords:}

Patient satisfaction

Community pharmacist

India

Quality of service

Patient-reported outcomes

\begin{abstract}
A B S T R A C T
Introduction: Patient satisfaction is an indicator in identifying and assessing the patient health-related needs, it is an important factor in determining the health care facilitates being delivered to the patients. The Community Pharmacist-led quality of services can be accessed through patient-reported outcomes (PROs). A cross-sectional survey was conducted to assess the level of client/patient satisfaction towards the services provided by the Community Pharmacist and factors affecting it.

Methods: A descriptive questionnaire-based cross-sectional study was conducted for a period of 3 months targeting general community adults who visit community pharmacy settings. Well-trained student pharmacists collected data from the subjects through an interview and the statistical analysis was done using SPSS v 14.

Results: A total of 314 participants were included in the study with a mean age of 24.39 years and standard deviation of 9.27 years. A higher number of participants were poorly satisfied (39.5\%) with the quality of patient counseling; only fewer (2.2\%) participants marked the quality of patient counseling delivered by the pharmacist as excellent. Level of satisfaction was higher for the male participants as compared to female participants, with an adjusted odds ratio of 2.541 at $95 \%$ CI $1.221-5.286$ with a significant p-value of 0.017 .

Conclusion: This paper provides an overview of the quality of services provided by Community Pharmacist in India. There is an immense need to organize the continuing education programs for the Community Pharmacist by employing social and administrative pharmacy tools to improve the services.
\end{abstract}

\section{Introduction}

Over the past decade, there observed a dramatic shift in the role of Community Pharmacists by transferring themselves as a patientcentred, beyond just restricting to medications dispensing. ${ }^{1}$ As the name by itself infers that they are the Pharmacists who strive for the welfare and well-being of the community concerning patient-care advocacy. ${ }^{2}$ The Community Pharmacists play an essential role in enhancing patient's health-related quality of life by attaining specific positive outcomes that are important from the patient perspective which can potentially reduce their disease and economic burden as well. ${ }^{3}$

Modernization in the field of Pharmacy Practice that has led to Pharmacist involvement in offering various Clinical Pharmacy Services
(CPS) such as, the drug information services, disease counseling, drug storage \& administration procedures, blood pressure, and blood sugar monitoring, etc. for the patient well-being. ${ }^{4}$ Among the various vital factors, patients' satisfaction would always be on the top of the list for any country in assessing the quality of the healthcare system. ${ }^{5}$ Patient satisfaction is the degree of positive feeling that patients experience having used a service. It acts as an indicator in identifying and assessing the patient health-related needs. The Community Pharmacist-led quality of services can be accessed through patient-reported outcome (PRO) which are solely based on the patient's satisfaction towards the services delivered on a visit to the pharmacy. ${ }^{3}$ Patient satisfaction towards pharmacy services might vary by a variety of factors such as waiting time, patient expectations, quality services, pharmacy setting \&

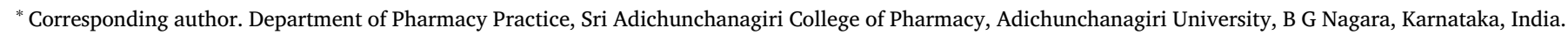
Tel.: +919886880633.

E-mail addresses: manikchhabra57@gmail.com (M. Chhabra), sknanu06@gmail.com (S.K. Gudi), muhammedrashid2@gmail.com (M. Rashid), aadi.goyal@yahoo.com (A. Goyal), ramantripathi2@gmail.com (R.K. Tripathi), ananthkashyap77@gmail.com (A. Kashyap). 
facilities, convenience, and availability of medications. ${ }^{6,7}$

Various studies that addressed this question in the past yielded disproportionate results. ${ }^{4,} 8-10$ However, the findings from the developed countries such as the United States of America, Canada, Australia, United Kingdom, and Europe inferred a positive opinion towards community pharmacy services. ${ }^{11-14}$ Thus, the rationale for conducting this study is to explore the patients' satisfaction towards Community Pharmacy Services from the Indian perspective, as the current evidence is not certain about the findings. As a result, as an initiation, a crosssectional survey was conducted in the north-west part of India to study the level of patient satisfaction towards the services provided by the Community Pharmacist and factors affecting the level of satisfaction.

\section{Methodology}

\subsection{Study design}

A descriptive questionnaire-based cross-sectional study was conducted for the period of 3 months from April to June 2018 targeting general community adults who visit community pharmacy settings after taking inform consent form. The study was commenced after getting approval from the Institutional Ethics Committee and all the studied participants were voluntarily included after obtaining informed consent form from all the study participants.

\subsection{Study subjects and selection criteria}

Study participants were recruited strictly as per the inclusion criteria, i.e., subjects of either gender with $\geq 18$ years of age, who were willing to participate in the study, and who has visited the community pharmacy in past six months of time for refilling the prescription. Proportionate random sampling was employed in selecting the samples from the population. All the study participants were informed about the objective of the study, and informed consent was taken from all the study participants before the data collection.

\subsection{Sample size}

The minimum of 300 sample size was calculated using the Raosoft software at a $95 \%$ confidence interval with $5 \%$ margin of error with the response rate of $29 \% .{ }^{15}$ As a result, the study analysis was comprised of 314 participants.

\subsection{Questionnaire and data collection process}

The study questionnaire was prepared after reviewing the similarly conducted and published studies around the globe. The questionnaire was undergone for the content validation by the two faculties from Pharmacy field, two from medical sciences, comments of each faculty member were addressed, and changes were made to get the final questionnaire. The study questionnaire comprised of the socio-demographic details of the participants and the sections that focused on the satisfaction of the subjects towards the services provided to them on a visit to the community pharmacy. In total, questionnaire consists of 20 questions in which satisfaction was based on five Likert scale items; (one stands for poor satisfaction, two for fair, three for good, four for very good, and five stands for excellent satisfaction respectively). Before the actual study commences, the study questionnaire was tested on 35 subjects, as a reliability measure, and they were not included in the final analysis. Data were collected from the subjects through an interview by well-trained student pharmacists with regards to seeking of permission and informed consent process before the data collection.

\subsection{Statistical methods}

Data was entered into Statistical Package for Social Sciences (SPSS)
Table 1

Socio-demographic variables of the study participants.

\begin{tabular}{|c|c|c|}
\hline Socio-Demographic Variables & Number (n) & Percentage (\%) \\
\hline \multicolumn{3}{|l|}{ Gender } \\
\hline Male & 124 & 39.5 \\
\hline Female & 190 & 60.5 \\
\hline \multicolumn{3}{|l|}{ Age Groups (Years) } \\
\hline $18-29$ & 261 & 83.1 \\
\hline $30-39$ & 22 & 7.0 \\
\hline $40-49$ & 31 & 9.9 \\
\hline \multicolumn{3}{|l|}{ Marital Status } \\
\hline Single & 238 & 75.8 \\
\hline Married & 76 & 24.2 \\
\hline \multicolumn{3}{|l|}{ Educational Status } \\
\hline Illiterate & 21 & 6.7 \\
\hline Primary School & 12 & 3.8 \\
\hline High School & 10 & 3.2 \\
\hline Higher Secondary School & 48 & 15.3 \\
\hline Diploma & 71 & 22.6 \\
\hline Graduate & 124 & 39.5 \\
\hline Post Graduate & 27 & 8.6 \\
\hline $\mathrm{PhD}$ & 1 & 0.3 \\
\hline \multicolumn{3}{|l|}{ Employment Status } \\
\hline Unemployed & 207 & 65.9 \\
\hline Private & 39 & 12.4 \\
\hline Government & 27 & 8.6 \\
\hline Housewife & 12 & 3.8 \\
\hline Others & 29 & 9.2 \\
\hline \multicolumn{3}{|l|}{ Type of Worker } \\
\hline Health Care Worker & 130 & 41.4 \\
\hline Non-Health Care Worker & 184 & 58.6 \\
\hline \multicolumn{3}{|l|}{ Residence } \\
\hline Rural & 164 & 52.2 \\
\hline Urban & 150 & 47.8 \\
\hline \multicolumn{3}{|l|}{ Chronic Health Illness } \\
\hline Absent & 289 & 92.0 \\
\hline Present & 25 & 8.0 \\
\hline \multicolumn{3}{|l|}{ Type of Pharmacy Visitor } \\
\hline Chain & 6 & 1.9 \\
\hline Private & 123 & 39.2 \\
\hline Both & 185 & 58.9 \\
\hline \multicolumn{3}{|l|}{ Health Insurance } \\
\hline No & 299 & 95.2 \\
\hline Yes & 15 & 4.8 \\
\hline \multicolumn{3}{|c|}{ No of Visits to Pharmacy in Past 6 Months } \\
\hline $1-5$ & 286 & 91.1 \\
\hline $6-10$ & 25 & 8.0 \\
\hline $11-15$ & 2 & .6 \\
\hline $16-20$ & 1 & .3 \\
\hline \multicolumn{3}{|l|}{ Time Spent in Pharmacy } \\
\hline $1-15 \mathrm{~min}$ & 232 & 73.9 \\
\hline $16-30 \mathrm{~min}$ & 76 & 24.2 \\
\hline $31-45 \min$ & 6 & 1.9 \\
\hline
\end{tabular}

v. 14, analyzed for both descriptive statistics and inferential statistics. Chi-square and binary logistic regression were used and a p-value of $<0.05$ was considered as significant.

\section{Results}

\subsection{Socio-demographic variables}

Of 314 study participants, the mean age was found to be 24.39 years with standard deviation of 9.27 years. Most of the participants (83.1\%) were belonging to the age group of 18-29 years, which infers that the cohort comprises of the younger adults. Among the participants, more than half of them $(60 \%)$ were females, $75.8 \%$ were single, and more than one-third (39.5\%) of them were graduated; however, $65.9 \%$ of the participants who responded to the survey were unemployed. About half of the participants $(52.2 \%)$ were from rural areas, and most of the respondents (92\%) were free from having any chronic illness. The rest of the socio-demographic variables are detailed in Table 1.

Among the study participants, most of them (92.7\%) were over the 
Table 2

Type of drug therapy user.

\begin{tabular}{lll}
\hline Type of Drug Therapy User & Number (n) & Percentage (\%) \\
\hline OTC & 291 & 92.7 \\
Anxiolytics & 2 & 0.6 \\
Anti-Hypertensive + Anti-Diabetes & 16 & 5.1 \\
Ayurvedic Medicines & 3 & 1.0 \\
Antibiotics & 2 & 0.6 \\
\hline
\end{tabular}

Table 3

Patient counseling quality indicators.

\begin{tabular}{llc}
\hline Patient Counseling Quality Indicators & Number (n) & Percentage (\%) \\
\hline Average Time Spent on Patient Counseling & \\
$1-15$ min & 297 & 94.6 \\
16-30 min & 17 & 5.4 \\
Mode of Patient Counseling & & \\
Not Received & 91 & 29.0 \\
Verbal & 175 & 55.7 \\
Non-Verbal & 48 & 15.3 \\
Aids Used for Patient Counseling & & \\
No Aid & 162 & 51.6 \\
Pictograms & 26 & 8.3 \\
Videos & 8 & 2.5 \\
Labels & 100 & 31.8 \\
Information Leaflets & 6 & 1.9 \\
Pictograms + Labels & 12 & 3.8 \\
\hline
\end{tabular}

counter (OTC) medication users, while $5.1 \%$ of them were on antihypertensive and antidiabetic drugs. Interestingly, only $0.6 \%$ of them were using antibiotics and anxiolytic drugs. The proportions of all other medications were detailed in Table 2.

\subsection{Patient counseling quality indicators}

From our study findings, the average time spent by the pharmacist on patient counseling for most of the study participants (94.6\%) was found between 1 and $15 \mathrm{~min}$. The mode of patient counseling used by the pharmacist for half of the candidates (55.7) was a verbal while, $2.9 \%$ of participants responded that they never received any counseling, and $43(15.3 \%)$ of participants received non-verbal mode of patient counseling. Unfortunately, half of the participants (51.6\%) responded that their pharmacist does not use any aid for patient counseling, while very few responded that their pharmacist uses patient information leaflet as an aid for patient counseling. The rest of the information on time spent, modes used, and aids used by the community pharmacists are detailed in Table 3.

\subsection{Patient's satisfaction with pharmacy services}

Unfortunately, more than one-third of the study participants were poorly satisfied (39.5\%) with the quality of patient counseling, and only fewer participants $(2.2 \%)$ marked the quality of patient counseling delivered by the community pharmacist as excellent. More than onethird of the participants (39.5\%) had marked waiting area of pharmacy as fair, while $2.9 \%$ marked it as excellent. From the study findings, it was observed that nearly one-third $(31.8 \%)$ of the participants were poorly satisfied with the advice of pharmacist on non-pharmacological treatment, while only one participant $(0.3 \%)$ marked it as excellent. Only $31.8 \%$ of the participants had marked behaviour of the pharmacist as good, while $12.7 \%$ of participants marked it as poor. Interestingly, $31.2 \%$ of the participants marked as good for pharmacist suggesting the generic medicines, while very few participants (5.4\%) were highly satisfied with it. The overall satisfaction of participants towards the services provided by the community pharmacist was good. The rest other parameters of patient satisfaction toward the services provided by the community pharmacist are detailed in Table 4.

\subsection{Factors affecting the level of satisfaction}

From the study findings, the level of satisfaction was noticed as higher for the male participant when compared to the female participant with an adjusted odds ratio of 2.541 (95\% CI; 1.221-5.286) at pvalue 0.017 . Majority of the participants in the age group of 18-29 were least satisfied with the services provided by the community pharmacist with an adjusted odds ratio of 0.866 (95 CI; 0.261-2.869). On the other

Table 4

Level of satisfaction among participants towards the services provided by community pharmacist.

\begin{tabular}{|c|c|c|c|c|c|c|}
\hline Question & Poor $(\%)$ & Fair $(\%)$ & Good (\%) & $\begin{array}{l}\text { Very Good } \\
(\%)\end{array}$ & Excellent (\%) & Chi Square, $\mathrm{P}$ value \\
\hline Quality of Patient Counseling I Receive from My Pharmacist & $124(39.5)$ & $82(26.1)$ & $71(22.6)$ & $30(9.6)$ & $7(2.2)$ & $125.68,<0.001^{*}$ \\
\hline Waiting area of Pharmacy I Visit & $72(22.9)$ & $125(39.8)$ & $76(24.2)$ & $32(10.2)$ & $9(2.9)$ & $126.92,<0.001^{*}$ \\
\hline Pharmacist's Advice on Non-pharmacological Treatment & $100(31.8)$ & $80(25.5)$ & $99(31.5)$ & $25(8)$ & $1(0.3)$ & $200.17,<0.001^{*}$ \\
\hline Availability of Drugs Stock (Adequate Inventory) & $50(15.9)$ & $39(12.4)$ & $101(32.2)$ & $83(26.4)$ & $41(13)$ & $49.79,<0.001^{*}$ \\
\hline Behaviour of my Pharmacist & $40(12.7)$ & $47(15)$ & $100(31.8)$ & $82(26.1)$ & $45(14.3)$ & $45.20,<0.001^{*}$ \\
\hline $\begin{array}{l}\text { Suggestion of my Pharmacist for Substitution with Generic Drugs (Low Price Drugs } \\
\text { with same Results) }\end{array}$ & $76(24.2)$ & $68(21.7)$ & $98(31.2)$ & $55(17.5)$ & $17(5.4)$ & $57.31,<0.001^{*}$ \\
\hline My Pharmacist Maintains Privacy during consultation & $77(24.5)$ & $102(32.5)$ & $77(24.5)$ & $44(14)$ & $14(4.5)$ & $36.06,<0.001^{*}$ \\
\hline My Pharmacist Understands me Well & $40(12.7)$ & $69(22)$ & $115(36.6)$ & $66(21)$ & $24(7.6)$ & $76.41<0.001^{*}$ \\
\hline Satisfaction on Advise of my Pharmacist & $54(17.2)$ & $68(21.7)$ & $117(37.3)$ & $51(16.2)$ & $24(4.6)$ & $77.65,<0.001$ \\
\hline Satisfaction on the bill charged for the medicines by my Pharmacist & $68(21.7)$ & $63(20.1)$ & $108(34.4)$ & $53(16.9)$ & $22(7)$ & $268,<0.001^{*}$ \\
\hline Information Provided by my Pharmacist on Drug Administration & $78(24.8)$ & $63(20.1)$ & $80(25.5)$ & $76(24.2)$ & $17(5.4)$ & $44.57,<0.001^{*}$ \\
\hline Satisfaction on Drug Information Provided by Pharmacist & $78(24.8)$ & $93(29.6)$ & $63(20.1)$ & $46(14.6)$ & $34(10.8)$ & $35.9,<0.001^{*}$ \\
\hline $\begin{array}{l}\text { My Pharmacist dispenses the Narcotic and Psychotropic Substances on Prescription } \\
\text { and handles with Extreme Care }\end{array}$ & $145(72)$ & $72(22.9)$ & $44(14)$ & $33(10.5)$ & $20(6.4)$ & $157.88,<0.001^{*}$ \\
\hline $\begin{array}{l}\text { Satisfaction on information being provided by Pharmacist on Poisoning and its } \\
\text { management }\end{array}$ & $94(29.9)$ & $92(29.3)$ & $98(31.2)$ & $20(6.4)$ & $10(3.2)$ & $122.37,<0.001^{*}$ \\
\hline $\begin{array}{l}\text { Satisfaction with the Pharmacist's responsibility towards Handling of Prescription } \\
\text { Drugs }\end{array}$ & $82(26.1)$ & $94(29.9)$ & $78(24.8)$ & $43(13.7)$ & $17(5.4)$ & $64.9,<0.001^{*}$ \\
\hline Satisfaction on Advise of my Pharmacist on Family Planning & $107(34.1)$ & $60(19.1)$ & $86(27.4)$ & $48(15.3)$ & $13(4.1)$ & $82.78,<0.001^{*}$ \\
\hline Satisfaction on Advise of my Pharmacist on Hygiene Maintenance & $67(21.3)$ & $76(24.2)$ & $112(35.7)$ & $44(14)$ & $15(4.8)$ & $83.61,<0.001^{*}$ \\
\hline Advise on Management of Minor Ailments like Cold Flue, Diarrhea, Vomiting etc. & $85(27.1)$ & $66(21)$ & $79(25.2)$ & $63(20.1)$ & $19(6.1)$ & $43.0,<0.001^{*}$ \\
\hline $\begin{array}{l}\text { My Satisfaction on Ambulatory Services like monitoring of BP, RBS/FBS provided by } \\
\text { my Pharmacist }\end{array}$ & $95(30.3)$ & $71(22.6)$ & $78(24.8)$ & $40(12.7)$ & $30(9.6)$ & $46.7,<0.001^{*}$ \\
\hline Overall Satisfaction towards the Services Provided by Pharmacist & $29(9.2)$ & $60(19.1)$ & $129(41.1)$ & $79(25.2)$ & $17(5.4)$ & $125.68,<0.001^{*}$ \\
\hline
\end{tabular}


Table 5

Factors associated with the level of satisfaction among the study participants.

\begin{tabular}{|c|c|c|c|c|c|}
\hline \multirow[t]{2}{*}{ Variables } & \multicolumn{2}{|c|}{ Satisfaction } & \multirow[t]{2}{*}{ COR $(95 \% \mathrm{CI})$} & \multirow[t]{2}{*}{ AOR $(95 \% \mathrm{CI})$} & \multirow[t]{2}{*}{$P$} \\
\hline & Low & High & & & \\
\hline \multicolumn{6}{|l|}{ Gender } \\
\hline Male & 80 & 44 & $1.490(0.910-2.440)$ & $\begin{array}{l}2.541 \\
(1.221-5.286)\end{array}$ & 0.017 \\
\hline Female & 138 & 52 & 1 & 1 & \\
\hline \multicolumn{6}{|c|}{ Age Category (in Years) } \\
\hline $18-29$ & 181 & 79 & $0.866(0.261-2.869)$ & $\begin{array}{l}1.496 \\
(0.619-3.617)\end{array}$ & 0.371 \\
\hline $30-39$ & 13 & 10 & $0.631(0.164-2.431)$ & $\begin{array}{l}2.637 \\
(0.812-8.569)\end{array}$ & 0.107 \\
\hline $40-49$ & 24 & 7 & 1 & 1 & \\
\hline \multicolumn{6}{|c|}{ Marital Status } \\
\hline Single & 163 & 75 & $1.205(0.680-2.136)$ & $.806(0.267-2.433)$ & 0.702 \\
\hline Married & 55 & 21 & 1 & 1 & \\
\hline \multicolumn{6}{|c|}{ Chronic Health Illness } \\
\hline Absent & 199 & 90 & $1.432(0.553-3.707)$ & $\begin{array}{l}1.525 \\
(0.399-5.819)\end{array}$ & 0.537 \\
\hline $\begin{array}{l}\text { Present } \\
\text { Residence }\end{array}$ & 19 & 6 & 1 & 1 & \\
\hline Rural & 113 & 52 & $0.911(0.563-1.474)$ & $\begin{array}{l}1.065 \\
(0.568-1.998)\end{array}$ & 0.845 \\
\hline Urban & 105 & 44 & 1 & 1 & \\
\hline \multicolumn{6}{|c|}{ Type of Pharmacy Visited } \\
\hline Chain & 5 & 1 & $\begin{array}{l}2.906 \\
(0.333-25.394)\end{array}$ & $\begin{array}{l}0.371(0.038 \\
3.578)\end{array}$ & 0.391 \\
\hline Private & 96 & 27 & $2.066(1.227-3.480)$ & $\begin{array}{l}0.457 \\
(0.229-0.914)\end{array}$ & 0.27 \\
\hline Both & 117 & 68 & 1 & 1 & \\
\hline \multicolumn{6}{|c|}{ Health Insurance } \\
\hline No & 206 & 93 & $0.536(0.165-1.740)$ & $\begin{array}{l}0.536 \\
(0.165-1.740)\end{array}$ & 0.299 \\
\hline Yes & 12 & 3 & 1 & 1 & \\
\hline \multicolumn{6}{|c|}{ Employment Status } \\
\hline Unemployed & 144 & 63 & $1.132(0.437-2.929)$ & $\begin{array}{l}0.925 \\
(0.308-2.782)\end{array}$ & 0.890 \\
\hline Private & 26 & 13 & $1.212(0.356-4.123)$ & $\begin{array}{l}1.134 \\
(0.288-4.466)\end{array}$ & 0.857 \\
\hline Government & 19 & 8 & $0.917(0.255-3.296)$ & 1.078.(254-4.575) & 0.918 \\
\hline Housewife & 9 & 3 & $0.940(0.166-5.315)$ & $\begin{array}{l}1.282 \\
(0.186-8.856)\end{array}$ & 0.801 \\
\hline Others & 20 & 9 & 1 & 1 & \\
\hline
\end{tabular}

hand, participants who did not have the health insurance were least satisfied with the services, and unemployed participants were less satisfied with the quality of service provided by the community pharmacist with an adjusted odds ratio of 0.925 (95\% CI; 0.308-2.782). All the other factors affecting the quality of services are well detailed in Table 5.

\section{Discussion}

As survey serves as an effective tool in bridging the gap between the services delivered and the expectations of participants towards the services, we attempted to evaluate the quality of services provided by the community pharmacist and opinion of the patients towards the services delivered. ${ }^{8}$ The findings of this study have revealed that the public has much expectation towards the services being provided by their community pharmacist.

The findings of overall satisfaction among our study participants were found to be similar with the study conducted by Surur S A et al. in north-west Ethiopia, ${ }^{16}$ while the study conducted in Botswana had shown a higher level of satisfaction as compared to the findings of our study. The reason for the lower level of satisfaction in our study might be due to the difference in the practice of pharmacy in India. ${ }^{17}$ The majority of the participants were poorly satisfied and wanted the waiting area of the pharmacy to be comfortable, and these findings were similar to the study conducted by Surur S A et al.,. ${ }^{16}$ The reason for the demand of a comfortable waiting area would be, as most often sick and diseased patient visit pharmacy to get their prescriptions refilled, they prefer to sit in a comfortable place and wait for their turn. Most of the participants in our study were poorly satisfied with the quality of patient counseling given to them, which was lower as compared to the study findings by Surur S A et al., ${ }^{16}$ This indicates that there is a need to sensitize and skill the community pharmacist of Punjab on the patient counseling and its importance. The pharmacists' advice on the non-pharmacological management of diseases was on the lower level of satisfaction, in fact, the pharmacist has to make his/her clients aware about the available non-pharmacological options for their treatment. $^{18}$

As best of the authors' knowledge, this is the first study of this kind in India, which tried to assess the satisfaction of patients in context to the services and facilities provided by the community pharmacist. The results of the previously conducted studies on patients' perception and satisfaction towards the services provided were varied from country to country. In a study conducted at Al-Jabar ENT hospital, Saudi Arabia had only $61.2 \%$ of patients who were satisfied by the services provided by the pharmacist, while the similar study conducted in Malta and Malaysia had almost $95 \%$ of the patient satisfaction rate. ${ }^{12,19}$

Most of the participants were poorly satisfied with pharmacist's handling of Psychotropic and narcotic drugs which is a serious concern, and it cannot be ignored. As per the best of our knowledge, we did not find any study, which reported the patients' satisfaction on the handling of Psychotropic and narcotic drugs by a pharmacist. Satisfaction of other services as poison information services, information on home remedies, hygiene maintenance, etc. provided by the pharmacist was found to be satisfactory. In contrast, a study conducted in Malta had reported that most of the patients were satisfied with the services provided by the pharmacist. In our current study, we found that people claimed the poor advice of a pharmacist to the public towards family planning.

Moreover, from our survey we found that most of the males were satisfied with the services provided by the community pharmacist as compared to female, this may be due to lack of interaction due to gender difference, as in India most of the pharmacist are male. On the other hand, patients without health insurance had the least overall satisfaction, might be due to lack of communication. Unemployed people and participants belonging to age group 18-29 years were also least satisfied with the overall quality of the services delivered to them. The reason behind the lower level of satisfaction among unemployed people can be lack of education, and it might be difficult for them to learn about drugs and disease conduction. The reason behind this might be the higher expectations from a pharmacist. It is a fundamental duty of the pharmacist to provide the services to all the people without any discrimination.

\section{Conclusion}

In a nutshell, the satisfaction level among the study participants of north-west India was found to be low. The Pharmacy licensing authorities in India should organize continuing education programs for the Community Pharmacist in order to enhance their quality of the services. The level of satisfaction varied by different socio-economic variables including gender, age group, marital status, occupation, and health insurance; which must be investigated for their strength of associations by using quantitative study designs in the near future.

\section{Limitations}

The major limitation of this study would be the generalizability of its results to the entire country, as the study is restricted to only northwestern part of India. 


\section{Conflicts of interest}

The Authors declare no conflict of interest.

\section{Author's contribution}

All the authors have equal contribution in designing the research, collecting data and drafting the manuscript.

\section{Financial support}

No funding was received for the conduct of the study.

\section{Acknowledgement}

The authors would like to thank all the authors who were involved in data collection and drafting of the manuscript.

\section{Appendix A. Supplementary data}

Supplementary data to this article can be found online at https:// doi.org/10.1016/j.cegh.2019.02.001.

\section{References}

1. Sabater-Galindo M, de Maya SR, Benrimoj SI, Gastelurrutia MA, Martínez-Martínez F, Sabater-Hernández D. Patients' expectations of the role of the community pharmacist: development and testing of a conceptual model. Res Soc Adm Pharm. 2017;13(2):313-320.

2. Hill WT. White Paper on Pharmacy Student Professionalism: what we as pharmacists believe our profession to be determines what it is. J Am Pharm Assoc (Wash). 2000;40(1):96-102.

3. Jackson JL, Chamberlin J, Kroenke K. Predictors of patient satisfaction. Soc Sci Med.
2001;52(4):609-620

4. Rayes IK, Hassali MA, Abduelkarem AR. The role of pharmacists in developing countries: the current scenario in the United Arab Emirates. Saudi Pharmaceut $J$. 2015;23(5):470-474.

5. Kravitz R. Patient satisfaction with health care: critical outcome or trivial pursuit? J Gen Intern Med. 1998;13(4):280-282.

6. Alturki M, Khan TM. A study investigating the level of satisfaction with the health services provided by the Pharmacist at ENT hospital, Eastern Region Alahsah, Kingdom of Saudi Arabia. Saudi Pharmaceut J. 2013;21(3):255-260.

7. Ayalew MB, Taye K, Asfaw D, et al. Patients'/clients' expectation toward and satisfaction from pharmacy services. J Res Pharm Pract. 2017;6(1):21.

8. Al-Arifi MN. Patients' perception, views and satisfaction with pharmacists' role as health care provider in community pharmacy setting at Riyadh, Saudi Arabia. Saudi Pharmaceut J. 2012;20(4):323-330.

9. El Hajj MS, Salem S, Mansoor H. Public's attitudes towards community pharmacy in Qatar: a pilot study. Patient Prefer Adherence. 2011;5:405.

10. Matowe L, Al-Kandery A, Bihzad SM. Pharmacy in Kuwait. Am J Health Syst Pharm. 2003;60(15):1591-1592.

11. Catic T, Jusufovic FI, Tabakovic V. Patients perception of community pharmacist in Bosnia and Herzegovina. Mater Soc Med. 2013:25(3):206

12. Wirth F, Tabone F, Azzopardi LM, Gauci M, Zarb-Adami M, Serracino-Inglott A. Consumer perception of the community pharmacist and community pharmacy services in Malta. J Pharmaceut Health Serv Res. 2010;1(4):189-194.

13. Bornman S, Truter I, Venter DJ. Public perception of community pharmacists in South Africa: a preliminary study. Health SA Gesondheid. 2006;11(3):27-40.

14. Anderson C. Health promotion by community pharmacists: consumers' views. Int $J$ Pharm Pract. 1998;6(1):2-12.

15. Raosoft I. Sample size calculator. . Available from www.raosoft.com/samplesize; 2004.

16. Surur AS, Teni FS, Girmay G, Moges E, Tesfa M, Abraha M. Satisfaction of clients with the services of an outpatient pharmacy at a university hospital in northwestern Ethiopia: a cross-sectional study. BMC Health Serv Res. 2015;15(1):229.

17. Márquez-Peiró JF, Pérez-Peiró C. Evaluation of patient satisfaction in outpatient pharmacy. Farm Hosp. 2008;32(2):71-76.

18. Kang J, Rhew K, Oh JM, et al. Satisfaction and expressed needs of pharmaceutical care services and challenges recognized by patients in South Korea. Patient Prefer Adherence. 2017;11:1381

19. Lau B-T, Nurul-Nadiah-Auni A-R, Ng S-Y, Shuen-Wong N. Satisfaction of patients receiving value added-services compared to traditional counter service for prescription refills in Malaysia. Pharm Pract. 2018;16(1). 